\title{
BMJ Open What are the requirements for developing a successful national registry of auditory implants? A qualitative study
}

\author{
Rishi Mandavia, ${ }^{1}$ Alec Knight, ${ }^{2}$ Alexander W Carter, ${ }^{3}$ Connor Toal, ${ }^{4}$ \\ Elias Mossialos, ${ }^{3}$ Peter Littlejohns, ${ }^{2}$ Anne GM Schilder ${ }^{1}$
}

To cite: Mandavia R, Knight A, Carter AW, et al. What are the requirements for developing a successful national registry of auditory implants? A qualitative study. BMJ Open 2018;8:e21720. doi:10.1136/ bmjopen-2018-021720

- Prepublication history and additional material for this paper are available online. To view these files, please visit the journal online (http://dx.doi. org/10.1136/bmjopen-2018021720).

Received 16 January 2018 Revised 27 June 2018 Accepted 6 August 2018
D) Check for updates

(c) Author(s) (or their employer(s)) 2018. Re-use permitted under CC BY-NC. No commercial re-use. See rights and permissions. Published by BMJ.

${ }^{1}$ evidENT, UCL Ear Institute, Royal National Throat, Nose and Ear Hospital, London, UK ${ }^{2}$ Health Service and Population Research Department, King's College London, London, UK ${ }^{3}$ Centre for Health Policy, Imperial College London, London, UK

${ }^{4}$ School of Medicine, University College London, London, UK

Correspondence to

Mr. Rishi Mandavia;

rishimandavia@gmail.com

\section{ABSTRACT}

Objectives Hearing loss is an area of unmet need, and industry is targeting this field with a growing range of surgically implanted hearing devices. Currently, there is no comprehensive UK registry capturing data on these devices; in its absence, it is difficult to monitor clinical and cost-effectiveness and develop national policy. Recognising that developing such a registry faces considerable challenges, it is important to gather opinions from stakeholders and patients. This paper builds on our systematic review on surgical registry development and aims to identify the specific requirements for developing a successful national registry of auditory implants.

Design Qualitative study.

Participants Data were collected in two ways: (1) semistructured interviews with UK professional stakeholders; and (2) focus groups with patients with hearing loss. The interview and focus group schedules were informed by our systematic review on registry development. Data were analysed using directed content analysis. Judges mapped the themes obtained against a conceptual framework developed from our systematic review on registry development. The conceptual framework consisted of five categories for successful registry development: (1) planning, (2) registry governance, (3) registry dataset, (4) anticipating challenges, (5) implementing solutions.

Results Twenty-seven themes emerged from 40 semistructured interviews with professional stakeholders and 18 themes emerged from three patient focus groups. The most important factor for registry success was high rates of data completion. Benefits of developing a successful registry of auditory implants include: strengthening the evidence base and regulation of auditory implants, driving quality and safety improvements, increased transparency, facilitating patient decision-making and informing policy and guidelines development.

Conclusions This study identifies the requirements for developing a successful national registry of auditory implants, benefiting from the involvement of numerous professional stakeholder groups and patients with hearing loss. Our approach may be used internationally to inform successful registry development.
Strengths and limitations of this study

- This study adopted an inclusive and robust approach, involving multiple professional stakeholder groups and patients with hearing loss.

- Our findings built on a conceptual framework on successful surgical registry development, that was developed following our systematic review and narrative synthesis.

- The interview schedules were informed by our published systematic literature review and were piloted and updated before data collection.

- Interview and focus group data were extracted and analysed by two independent data judges, with further verification by a data auditor.

- We recognise that the use of purposive sampling for identifying professional stakeholders may have been prone to researcher bias.

\section{INTRODUCTION}

Hearing loss has been identified as a key public priority by the Department of Health (DoH) and UK policy-makers. ${ }^{1-3}$ In the UK, 10 million people suffer from hearing loss, with an estimated annual cost to the economy of $£ 30$ billion. ${ }^{14}$ Hearing loss has a major impact on social functioning and is associated with an increased risk of dementia. ${ }^{15-11}$ Importantly, the impacts of hearing loss are set to increase with our ageing population. ${ }^{89}$

Policy-makers, guideline developers, clinicians, researchers and industry have realised that hearing loss is an area of unmet need. ${ }^{1} 7$ This has resulted in increased investment in the development of surgically implanted hearing devices including cochlear implants (CIs), bone conducting hearing devices and middle ear implants.

While auditory implants have been widely adopted, UK registry data on patients with auditory implants are lacking. ${ }^{12-14}$ Safety incidents around other surgical implants such 
as the 'poly implant prostheses' breast implant and the 'metal-on-metal' hip implant highlight the dangers of not collecting such information. ${ }^{15-17}$ Conversely, successful registry initiatives such as the National Hip Fracture Database, the National Joint Registry and the National Audit Cardiac Surgery registry highlight the benefits of registry data. ${ }^{18-20}$ Hearing stakeholders, policy-makers and patients have recognised that, in the absence of registry data, it is difficult to regulate auditory implants, monitor clinical and cost-effectiveness, and ultimately develop appropriate guidelines and policy. ${ }^{2}$

A potential solution is to develop a national registry of all auditory implants. ${ }^{2}$ Recognising that developing such a registry faces considerable challenges, it is important to gather opinions from relevant stakeholders and patients with hearing loss. ${ }^{21}$ This paper builds on our recent systematic review ${ }^{22}$ on successful surgical registry development and aims to identify the specific requirements for developing a successful national registry of auditory implants.

\section{MATERIALS AND METHODS Ethical considerations}

To facilitate patient attendance, travel expenses were remunerated and gift vouchers were provided.

\section{Data collection}

Data were collected in two ways: (1) semistructured interviews with professional stakeholders (PSs); and (2) focus groups (FGs) with patients with hearing loss. The methodological orientation underpinning the study was content analysis, ${ }^{23}$ and the study protocol was designed in accordance with the Consolidated criteria for Reporting Qualitative research criteria. ${ }^{24}$

\section{Semistructured interviews with PSs \\ Participants}

We adopted a purposive sampling strategy to identify individuals who were especially knowledgeable about hearing loss and implants. ${ }^{25}$ Stakeholders were identified from a network of professionals known to the authors and their collaborators. The list of stakeholders was cross-checked by two independent individuals from separate institutions. At the end of each interview, interviewees were asked to provide contact details of stakeholders with relevant experience to our study. Stakeholders were approached via email invitation. Data analysis commenced after completion of the first interview. Stakeholders were recruited and interviewed until data saturation was reached. PS groups were located across the UK. Information on stakeholder groups can be seen in table 1 .

A total of 40 stakeholders were interviewed. This sampling approach led to a response rate of $89 \%$. Reasons for non-participation included: unable to schedule suitable time $(n=2)$ and non-response to invitation $(\mathrm{n}=3)$.
Table 1 Stakeholder group frequency

\begin{tabular}{ll}
\hline Stakeholder group & $\mathbf{n}$ \\
\hline Audiologists & 6 \\
\hline ENT surgeons & 9 \\
\hline Non-ENT surgical registry representatives & 7 \\
\hline ENT registry leads & 3 \\
\hline Industry & 4 \\
\hline Registry experts & 3 \\
\hline Commissioners & 2 \\
\hline Patient charity representatives & 2 \\
\hline National guidelines experts & 3 \\
\hline Policy experts & 3 \\
\hline Health economics experts & 2 \\
\hline Department of Health representatives & 3 \\
\hline National hearing body representatives & 4 \\
\hline
\end{tabular}

ENT, ear, nose and throat.

\section{Procedures}

Individual interviews lasted between 14 and $34 \mathrm{~min}$ and were digitally recorded and transcribed. Participation was voluntary, and transcripts were anonymised. Participants were interviewed between March 2015 and December 2016, either in person at the University College London (UCL) Ear Institute or via telephone. The semistructured interviews followed an interview schedule comprising 13 questions, each of which contained specific probes (see online supplementary appendix 1). The interview schedule was developed following our narrative systematic review on UK surgical registry development. ${ }^{22}$ The interviewer was an ENT Academic Clinical Trainee with expertise in health policy research. The interview schedule focused on (1) opinions on existing auditory implant registries, (2) the requirements of a successful registry and (3) the challenges of establishing a national registry of auditory implants and potential solutions.

The interview schedule was piloted on two professionals and updated following their feedback.

\section{FGs with patients with hearing loss Participants}

Adult patients with hearing loss and their family members were interviewed in three FGs, each comprising 6-7 participants. Participants were identified from a UCL Ear Institute database of patients who had given their consent to take part in clinical research. Participants were approached via email invitation. A total of 19 participants were included. Characteristics of participants are shown in table 2. Ten patients refused to participate due to: lack of time $(n=3)$, caring commitments $(n=3)$ and difficulty in travelling $(n=4)$. 


\begin{tabular}{|c|c|c|}
\hline $\begin{array}{l}\text { Patient } \\
\text { number }\end{array}$ & Characteristic & Location \\
\hline 1 & $\begin{array}{l}\text { Family member of patient } \\
\text { with bilateral hearing aids }\end{array}$ & Birmingham \\
\hline 2 & Unilateral $\mathrm{Cl}$ user & London \\
\hline 3 & $\begin{array}{l}\text { Family member of patient } \\
\text { with unilateral } \mathrm{Cl}\end{array}$ & London \\
\hline 4 & $\begin{array}{l}\text { Unilateral } \mathrm{Cl} \text { and unilateral } \\
\text { hearing aid user }\end{array}$ & Manchester \\
\hline 5 & $\begin{array}{l}\text { Family member of patient } \\
\text { with bilateral hearing aids }\end{array}$ & Birmingham \\
\hline 6 & Bilateral hearing aid user & Leeds \\
\hline 7 & Unilateral BAHA user & London \\
\hline 8 & Unilateral $\mathrm{Cl}$ user & Sheffield \\
\hline 9 & Bilateral $\mathrm{Cl}$ user & Oxford \\
\hline 10 & Bilateral $\mathrm{Cl}$ user & Oxford \\
\hline 11 & $\begin{array}{l}\text { Member of patient group of } \\
\text { patients with hearing loss }\end{array}$ & London \\
\hline 12 & Unilateral BAHA user & Leicester \\
\hline 13 & Unilateral $\mathrm{Cl}$ user & Norwich \\
\hline 14 & $\begin{array}{l}\text { Unilateral } \mathrm{Cl} \text { user and works } \\
\text { in a hearing-loss charity }\end{array}$ & London \\
\hline 15 & $\begin{array}{l}\text { Unilateral } \mathrm{Cl} \text { and unilateral } \\
\text { hearing aid user }\end{array}$ & London \\
\hline 16 & Bilateral BAHA user & London \\
\hline 17 & $\begin{array}{l}\text { Unilateral BAHA and } \\
\text { unilateral hearing aid }\end{array}$ & Brighton \\
\hline 18 & $\begin{array}{l}\text { Unilateral } \mathrm{Cl} \text { and unilateral } \\
\text { BAHA }\end{array}$ & Reading \\
\hline 19 & Bilateral $\mathrm{Cl}$ user & Swindon \\
\hline
\end{tabular}

$\mathrm{Cl}$, cochlear implant, BAHA: bone anchored hearing aid.

\section{Procedures}

The FGs explored 10 questions, each containing specific probes about a future national registry of auditory implants (see online supplementary appendix 2 ). The questions were developed from the same systematic review on UK surgical registry development. ${ }^{22}$ FGs took place in July 2016 at the UCL Ear Institute and were facilitated by the primary investigator and a patient and public involvement expert.

The FG discussions lasted between 90 and $105 \mathrm{~min}$. The discussions were recorded using a digital recorder and professionally transcribed. Transcripts were anonymised. The FG schedule was trialled on two patients and updated following their feedback.

\section{Analysis}

Data analyses were performed in two stages.

Stage 1: two data judges (RM and CT) qualitatively analysed the interview and FG transcripts separately using directed content analysis. ${ }^{23}$ Data judges independently read through the interview and FG transcripts and extracted data from the transcripts manually onto separate data extraction tables. The framework of the data extraction tables reflected the structure of the interview and FG schedules. The data judges independently made notes of themes arising from the extracted data and compared their analyses. Discrepancies were discussed and resolved. Amending the themes list was repeated until no new themes emerged. The data judges met periodically with the data auditor (AS) to discuss the analysis.

Stage 2: Judges independently mapped the themes obtained from the stakeholder interviews and FG responses against a conceptual framework developed from our systematic review on registry development. ${ }^{22}$ The conceptual framework consisted of five fundamental categories for successful registry development: (1) planning, (2) registry governance, (3) registry dataset, (4) anticipating challenges, (5) implementing solutions. ${ }^{22}$ Judges compared their findings, and discrepancies were discussed and resolved.

\section{Patient involvement}

- Patients with hearing loss helped inform the research question during previous FGs held at the UCL institute.

- Patients gave feedback on the wording of the FG schedule. Their feedback was used to update the schedule before carrying out the FG discussions.

- Patients were able to suggest the inclusion of their family members in the FGs.

- Results will be disseminated back to study participants during a consensus conference held at the UCL Ear Institute.

\section{RESULTS}

\section{Semistructured interviews with PSs}

All themes identified are presented below under each interview question. A summary of the extracted data giving rise each theme is provided. Table 3 summarises all themes identified.

PS question (Q) 1: What are your thoughts on the existing auditory implant registries available?

\section{Theme (T) 1a: Existing registries available}

Stakeholders were aware of the following UK auditory registries: the Ear Foundation Bone Anchored Hearing Aid registry, The Ear Foundation Bone Conduction Hearing Implant (BCHI) registry, Pochia CI registry, Bawtry Database, Auditbase, National Audit of Bilateral CIs, Auditbase, Otology Web Based database, Cochlear Paediatric Implanted Recipient Observational Study registry. Some implant centres and device manufactures have their own registries.

\section{T1b: Existing registries are limited}

Limitations of existing registries include: poor rates of data completion; not user-friendly; difficult to navigate and enter data; overly basic or complex datasets; 
Table 3 Themes identified from stakeholder interviews and patient FGs

\section{Semistructured interviews with PSs}

PS Q1. What are your thoughts on the existing auditory implant registries available?

PS Q2. Do you think a national registry of auditory implants will be of benefit?
T1a. Existing registries available

T2a. Improve safety and T2b. Promote research quality of care
T1b. Existing registries are limited and innovation
T2c. Facilitate commissioning and guideline development
T2d. Help patient decision-making
PS Q3. What do you think the main purpose or goal of the
registry should be?
PS Q4. How should the registry be led/who should make the decisions? 3a. To improve the quality and safety of care

T4a. Have steering committee
T5a. Dedicated management team

T6a. Registry dataset

T5b. Robust IT systems to verify data

T6b. Quality of life data included in the dataset?

\begin{tabular}{|c|c|c|c|c|}
\hline $\begin{array}{l}\text { PS Q7. What are the main challenges of establishing a } \\
\text { registry? }\end{array}$ & $\begin{array}{l}\text { T7a. 'Buy-in' and data } \\
\text { completion }\end{array}$ & T7b. Resource heavy & $\begin{array}{l}\text { T7c. Registry } \\
\text { governance }\end{array}$ & \\
\hline PS Q8. How can we overcome these challenges? & $\begin{array}{l}\text { T8a. Engage with } \\
\text { opinion leaders }\end{array}$ & $\begin{array}{l}\text { T8b. Registry } \\
\text { development and } \\
\text { design }\end{array}$ & $\begin{array}{l}\text { T8c. Make it } \\
\text { compulsory }\end{array}$ & $\begin{array}{l}\text { T8d. Make it clearly } \\
\text { useful }\end{array}$ \\
\hline $\begin{array}{l}\text { PS Q9. Should patients be involved in the registry and if } \\
\text { so how? }\end{array}$ & $\begin{array}{l}\text { T9a. Leadership and } \\
\text { development }\end{array}$ & $\begin{array}{l}\text { T9b. Accessing the } \\
\text { registry }\end{array}$ & T9c. Entering data & \\
\hline PS Q10. Who should own the data of the registry? & $\begin{array}{l}\text { T10a. Independent } \\
\text { national body }\end{array}$ & & & \\
\hline PS Q11. How should we fund the registry? & T11a. Multiple sources & $\begin{array}{l}\text { T11b. Levy on all } \\
\text { implants used }\end{array}$ & & \\
\hline $\begin{array}{l}\text { PS Q12. Should we publish data on specific surgeons } \\
\text { and hospitals? }\end{array}$ & $\begin{array}{l}\text { T12a. Wait until the } \\
\text { registry is established }\end{array}$ & & & \\
\hline $\begin{array}{l}\text { PS Q13. Overall what do you think is the most important } \\
\text { factor for making a registry successful? }\end{array}$ & $\begin{array}{l}\text { T13a. Data } \\
\text { completeness }\end{array}$ & & & \\
\hline
\end{tabular}

\section{FGs with patients with hearing loss}

FG Q1. What are your thoughts on developing a T1a. Improve quality and safety registry of patients that have surgically implanted of care hearing devices?

T2a. Formal patient

FG Q2. How do you think patients could be representation a registry?

\section{FG Q3. What type of information do you think} should be recorded in the registry?

\section{T3a. Registry dataset and} easy-to-understand outcome measure

FG Q4. Would you want to be able to access and T4a. Benefits of patient access add information into the registry?

T1b. Help develop national guidelines and policy
T1c. Facilitate patient decisionmaking
T1d. Challenges to registry development

\begin{tabular}{|c|c|c|c|}
\hline $\begin{array}{l}\text { FG Q5. How can we help get patients to input their } \\
\text { data and be involved in the registry? }\end{array}$ & $\begin{array}{l}\text { T5a. Make the registry useful for } \\
\text { patients }\end{array}$ & $\begin{array}{l}\text { T5b. Make the registry } \\
\text { simple and use } \\
\text { technology }\end{array}$ & $\begin{array}{l}\text { T5c. Inbuilt patient } \\
\text { discussion forum }\end{array}$ \\
\hline $\begin{array}{l}\text { FG Q6. Would you like the registry to contain } \\
\text { information on results of named surgeons or } \\
\text { hospitals? }\end{array}$ & $\begin{array}{l}\text { T6a. Inaccurate reflection of } \\
\text { practices }\end{array}$ & $\begin{array}{l}\text { T6b. Increase patient } \\
\text { choice }\end{array}$ & \\
\hline $\begin{array}{l}\text { FG Q7. How do you think the data should be } \\
\text { protected and kept confidential? Who should be } \\
\text { allowed to access your data? }\end{array}$ & T7a. Data governance & $\begin{array}{l}\text { T7b. Data protection } \\
\text { committee }\end{array}$ & \\
\hline
\end{tabular}

FG Q8. Who should own the data of the registry? T8a. Independent organisation

FG Q9. Registries are expensive to set up and maintain. How should the registry be paid for?

FG Q10. Overall, what do you think is the most important factor for making a registry successful? 
inappropriate outcome measures; too clinician-focused; unable to sufficiently inform clinical practice, commissioning or guidelines development.

PS Q2: Do you think a national registry of auditory implants will be of benefit?

\section{T2a: improve safety and quality of care}

A successful registry would be able to monitor national practices, improve quality of care, identify safety concerns and facilitate implant recall. The registry would also facilitate (inter)national comparison of practices and comparison between implants. Poorly performing centres could be identified and supported. Registry leads noted that their registries were associated with improved clinical standards, shorter waiting times and length of stay, and reductions in morbidity and mortality.

\section{T2b: promote research and innovation}

A registry would provide essential data to assess the clinical and cost-effectiveness of auditory implants. It would also facilitate research collaborations, provide data with external validity, refine indications for implantation and drive device improvements and innovations.

\section{T2c: facilitate commissioning and guideline development}

A registry would enable monitoring of national clinical activity, facilitating efficient implant procurement, fair distribution of resources and equitable access to care. The registry would also provide valuable information for guidelines and policy development.

\section{T2d: help patient decision-making}

A national registry would help patients make informed decisions by providing them with information on procedure effectiveness and risks.
PS Q3: What do you think the main purpose or goal of the registry should be?

\section{T3a: to improve the quality and safety of care}

The main purpose of the registry should be to improve the quality and safety of care provided while promoting transparency and patient choice. The registry should also aim to monitor practices and device effectiveness, drive clinical research and assist in the development of policy.

PS Q4: How should the registry be led/who should make the decisions?

\section{T4a: have a steering committee}

The registry should be led by an independent steering committee, with representation from: audiologists, an ENT UK representative, implant surgeons, commissioners, policy experts, a health economist, guideline developers, patients and a lay-member. Subcommittees would be responsible for separate areas, including funding, data collection, data verification and governance.

\section{PS Q5: How should the registry be managed/maintained?}

T5a: dedicated management team

The registry should be managed by a dedicated management team, responsible for: collecting data centrally, maximising data completion and verifying data. Each hospital should have its own data manager.

\section{T5b: robust information technology systems to verify data}

Robust information technology (IT) systems should be in place, to verify and clean data. Registry data can be verified by comparing it with Hospital Episode Statistics data.

PS Q6: Broadly speaking, what do you think should be included in the dataset?

T6a: registry dataset

Table 4 summarises the preoperative, intraoperative and postoperative data-items on which consensus was reached.

\section{Table 4 Stakeholder suggested data-items}

\begin{tabular}{lll}
\hline Preoperative & Operative & Postoperative \\
\hline $\begin{array}{l}\text { NHS number/patient identifier (linkable to } \\
\text { HES) }\end{array}$ & Name of hospital & Length of stay \\
Patient demographic details & Name of operation & Hearing test result at each follow-up \\
\hline Patient diagnosis & Date of surgery & Complications at each follow-up \\
\hline Indication & Grade of surgeon & Employment status \\
\hline Primary or revision & Side of surgery & \\
Cost of implant & Surgery start time & \\
Hearing test result & Surgical approach & \\
Comorbidities & Name, make and model of implant & \\
MDT outcome & Implant serial number & \\
Employment status & Intraoperative complication(s) & \\
Date of decision to operate & Surgery end time & \\
\hline
\end{tabular}

HES, Hospital Episode Statistics; MDT, multidisciplinary team; NHS, National Health Service. 
A consensus meeting would be required to establish the specifics of the dataset.

\section{T6b: quality of life data}

Quality of life (QoL) data helps provide meaningful outcomes and facilitates health economic analyses. However, it is challenging to reach consensus on QoL outcome measures, and QoL data collection is time consuming and may result in reduced data completion. Therefore, QoL data collection should be introduced when the registry is well established.

\section{PS Q7: What are the main challenges of establishing a registry?}

T7a: 'buy-in' and data completion

The main challenge would be achieving long-term 'buyin' and data completion. Reaching agreement on the registry dataset would also be a key challenge.

\section{T7b: resource heavy}

The registry would require considerable financial, human and time resources for initial set-up, data entry and registry maintenance.

\section{T7C: registry governance}

Data governance and legal factors are other challenges. These include compliance with data protection and information governance laws, maintaining data security, policing data access, appointing a steering committee, identifying data ownership, acquiring patient consent and ensuring data accuracy and quality.

\section{PS Q8: How can we overcome these challenges?}

\section{T8a: engage with opinion leaders}

Having opinion leaders as registry advocates would increase registry awareness. Support from influential organisations, such as DoH, the National Institute for Health and Care Excellence (NICE) and commissioning groups, would help maximise registry relevance and funding.

\section{T8b: registry development and design}

All stakeholder groups should be involved in registry development, and the registry must be simple, electronic and adaptable to maximise data completion and promote longevity. A minimal dataset should be employed that is quick to complete, with no free-text data entry. Legal, governance and IT experts should be consulted from the outset, with data verification systems in place. A pilot registry would provide user feedback and facilitate registry improvement before national launch.

\section{T8c: make it compulsory}

The most effective way to maximise data completion would be by making the registry compulsory for clinician revalidation and for commissioning. Financial incentives could be applied to hospitals, and data completion rates could be published.

\section{T8d: make it clearly useful}

Making the registry useful for stakeholders for publications, audits, revalidation, implant procurement and policy development would increase 'buy-in' and data completion. Registry achievements should be disseminated to increase registry awareness.

PS Q9: Should patients be involved in the registry and if so how? Patients should be involved in the registry in three different capacities.

\section{T9a: leadership and development}

A patient representative should be on the steering committee. This would help make the registry more accountable and meaningful.

\section{T9b: accessing the registry}

Patients should be given access to the registry, particularly to their own data. This would encourage data accuracy and completion. Safeguards would be needed to comply with data-protection and patient confidentiality.

\section{T9c: entering data}

It would be helpful and efficient for patients to enter their own data, particularly QoL data. However, data verification systems would be needed, and patient data entry would be complex and expensive; and should therefore be implemented once the registry is already well established.

PS Q10: Who should own the data of the registry?

T10a: independent national body

The registry should be owned by an independent national body such as: NHS England, DoH, the Secretary of State for Health and Public Health England. These bodies would provide longevity, impartiality, fair access and experience.

\section{PS Q11: How should we fund the registry?}

\section{T11a: multiple sources}

Funding should be requested from all stakeholder groups. Multiple income streams would provide financial security and increase engagement. Suggested funders included: ENT UK, DoH, patient charities, research grants, National Institute for Health Research, Medical Research Council, Action on Hearing Loss, healthcare providers, industry, The Ear Foundation, British Society of Audiology and The British Academy of Audiology.

\section{T11b: levy on all implants used}

A fee, applied to each implant used, would be a helpful source of income. The fee would be paid for by industry and the purchasing hospital.

\section{PS Q12: Should we publish data on specific surgeons and} hospitals?

\section{T12a: wait until the registry is established}

Potential benefits include: increased patient choice, trust, transparency and promoting a culture of learning. Negatives include: data being misleading if unadjusted for case mix, data poorly reflecting that outcomes are dependent 
on the entire healthcare team, reporting bias, risk-averse practices and reduced rates of data completion. Due to these risks, data should be reported once the registry is well established, with robust mechanisms for adjusted reporting.

PS Q13: Overall what do you think is the most important factor for making a registry successful?

T13a: data completeness

High levels of data completion and accuracy are essential. To achieve this, the most important factors include: involving stakeholders and patients during registry development, compulsory data entry, making the registry useful for all groups and having robust data processing systems.

\section{FGs with patients with hearing loss}

All themes identified are presented below under each interview question. A summary of the extracted data giving rise each theme is provided. Table 3 summarises all themes identified.

FG Q1: What are your thoughts on developing a registry of patients that have surgically implanted hearing devices?

T1a: improve quality and safety of care

A registry would identify implant problems early, permit recall in the event of safety concerns and allow manufacturers to evaluate their products and improve effectiveness while encouraging competition. It would enable national comparison of outcomes and promote research.

\section{T1b: help develop national guidelines and policy}

A national registry would help develop guidance and policy that would reduce variation between centres. It would also help commissioners plan services better, including efficient implant procurement.
T1c: facilitate patient decision-making

By providing accurate information on implant effectiveness, risks and new developments, a registry would help patients make decisions on their care.

\section{T1d: challenges to registry development}

Professionals may not input data, resulting in poor rates of data completion, and it would be challenging to reach agreement on the registry dataset and data ownership.

FG Q2: How do you think patients could be involved in developing, leading or managing such a registry?

T2a: formal patient representation

Patients should be formally involved in registry development and leadership. This would make the registry more relevant and useful for patients.

FG Q3: What type of information do you think should be recorded in the registry?

T3a: registry dataset and easy-to-understand outcome measure There should be a balance between comprehensibility and simplicity: comprehensive datasets would be too time consuming, while basic datasets would provide limited value. Table 5 summarises the data-items on which consensus was reached. The registry should include an outcome measure that is easily understandable by patients.

FG Q4: Would you want to be able to access and add information into the registry?

\section{T4a: benefits of patient access}

Patient access would make the registry more patient focused and help patients make decisions on their care.

\section{T4b: patients entering data}

Patients were keen to contribute to data entry via 'apps'. Paper-based entry could be used for patients not familiar with online platforms.

Table 5 Patient focus group suggested data-items

\begin{tabular}{|c|c|c|}
\hline Preoperative & Operative & Postoperative \\
\hline Occupation & Grade of surgeon & QoL \\
\hline Preoperative QoL & Indications for surgery & Implant problems \\
\hline Levels of hearing & Name of implant & Dates of follow-up appointments \\
\hline Type of hearing loss & Implant manufacturer & $\begin{array}{l}\text { Measure of cognitive status (for elderly } \\
\text { patients) }\end{array}$ \\
\hline Current hearing devices being used & Duration of surgery & $\begin{array}{l}\text { Outcome measure understandable by } \\
\text { patients }\end{array}$ \\
\hline Information on previous hearing treatments & Intraoperative complication(s) & \\
\hline
\end{tabular}

QoL, quality of life. 
FG Q5: How can we help get patients to input their data and be involved in the registry?

\section{T5a: make the registry useful for patients}

Making the registry useful for patients would increase patient involvement. This could be achieved by having a patient section containing relevant information for patients.

\section{T5b: make the registry simple and use technology}

The registry should be simple and easy to use. This could be facilitated by using technology including 'apps' and text message alerts to remind patients to enter data.

\section{T5c: inbuilt patient discussion forum}

A patient discussion forum within the registry would help engage patients. This forum would enable patients to learn from one another and share experiences.

FG Q6: Would you like the registry to contain information on results of named surgeons or hospitals?

T6a: inaccurate reflection of practices

Publishing this information may result in inaccurate reflection of practices. Surgeons with complex cases may have a higher risk of complications. Publication may result in surgeons becoming more risk-averse, and this data would not reflect that outcomes are dependent on the entire healthcare team. An independent committee should have access to this data and provide feedback and support where necessary.

\section{T6b: increase patient choice}

This information would help increase patient choice and transparency and trust, while giving surgeons incentive to improve practices.

FG Q7: How do you think the data should be protected and kept confidential? Who should be allowed to access your data?

\section{T7a: data governance}

Data should be anonymous, with patients identifiable only via a patient number. Patient consent should be obtained for data collection, and registry access should be password protected.

\section{T7b: data protection committee}

The registry should have a committee for data protection, with a patient representative. All healthcare professionals should be able to access the registry if necessary for patient care.

\section{FG Q8: Who should own the data of the registry?}

T8a: independent organisation

The registry should be owned by an independent body. Registry ownership by a single hospital, academic group or implant company could lead to conflicts of interest, or data manipulation and therefore reduced confidence in the registry.
FG Q9: Registries are expensive to set up and maintain. How should the registry be paid for?

\section{T9a: multiple sources}

Funding should be obtained from a mixture of sources, to avoid over-reliance on a single funder. All parties that benefit from the registry should contribute towards it. A fee should be charged for accessing registry data for research or industry purposes.

FG Q10: Overall, what do you think is the most important factor for making a registry successful?

T10a: data completeness

There was consensus among patients that the most important factor for registry success is high levels of data completion. To achieve this, patients and professional groups must be involved during the development and running of the registry.

\section{Organisation of themes into a conceptual framework}

The themes obtained from the interviews and FGs were mapped against a conceptual framework, consisting of five fundamental categories for successful registry development $^{22}$ (figure 1): (1) Planning includes setting registry objectives, appointing a steering committee, establishing registry management systems, acquiring long-term funding and defining registry ownership. (2) Registry governance involves appointing a data-protection committee and incorporating patient access and surgeon-specific data reporting once appropriate registry systems are in place. (3) Registry dataset includes selecting the fundamental data-items, having a free-text field, holding a dataset consensus meeting and implementing QoL data collection once the registry is well established. (4) Anticipating challenges consists of being aware of core challenges, including data completion and reaching consensus on registry dataset, resource requirements, data governance and legal factors. (5) Implementing solutions involves putting in place the following strategies to maximise registry success: compulsory data-input, advertise registry benefits, engage with influential groups, involve stakeholders and patients, make the registry user-friendly, have early input from legal, IT and governance experts.

\section{DISCUSSION}

\section{Summary of findings}

Figure 1 summarises the key requirements for developing a successful national registry of auditory implants.

\section{Relevance to existing research}

The call for surgical registries extends beyond auditory implants, with a UK and Europe-wide drive to establish registries for all surgical implants. ${ }^{26}$ Across the EU and UK, new implants can enter surgical practice on the basis of similarity to an existing implant, rather than on the basis of its own clinical effectiveness. ${ }^{26} 27$ Concerns over the evidence base for surgical implants have been raised by several bodies including the IDEAL collaborative, the EU and the House of Commons Science and Technology 


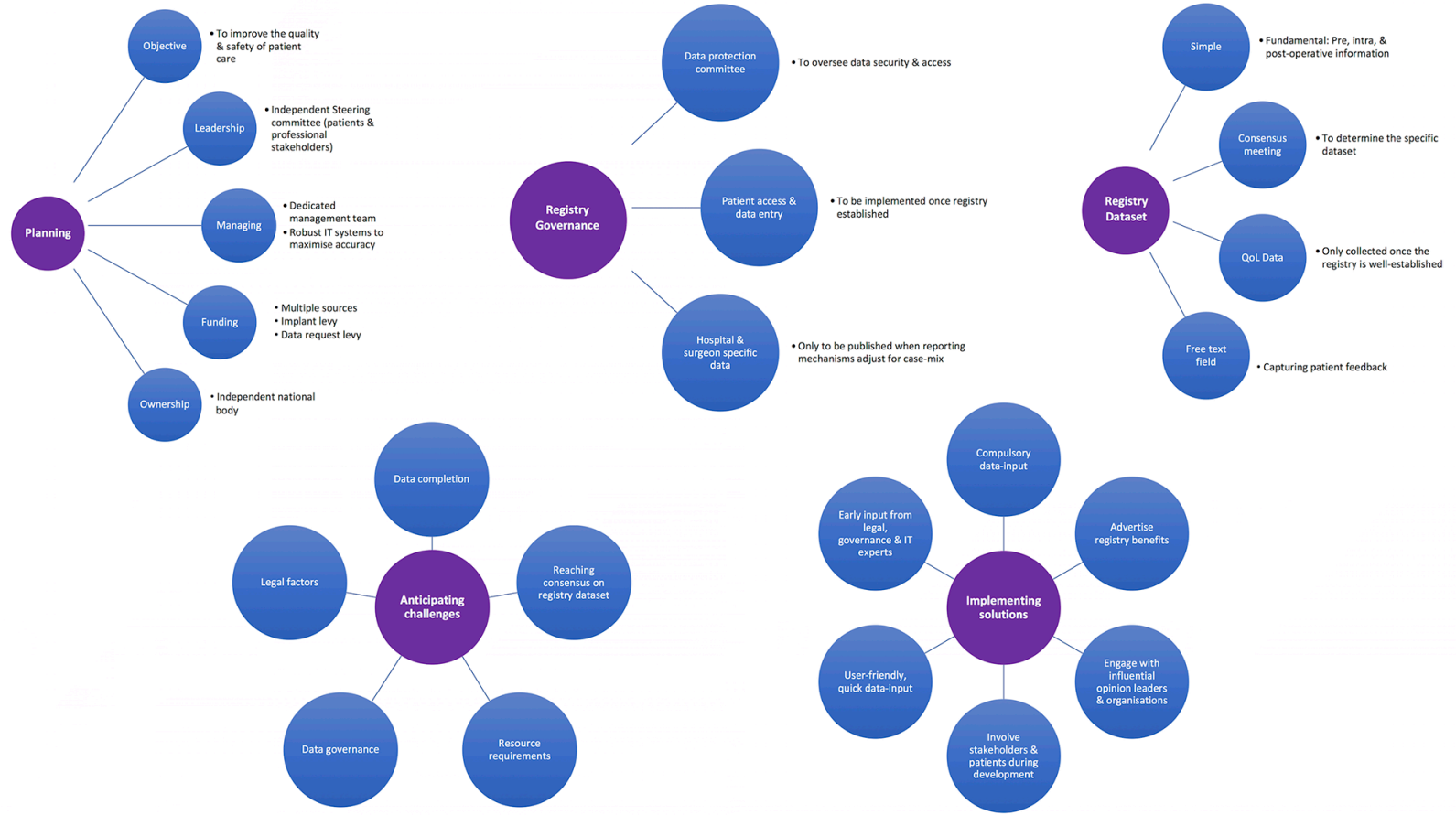

Figure 1 The key requirements for developing a successful national registry of auditory implants.

committee. ${ }^{2627}$ Registries represent a pragmatic approach to address these concerns. ${ }^{28-33}$ Unlike conventional clinical studies, registries can answer the fundamental questions required for policy and guideline development, namely: (1) Does it work? (2) Will it work here? (3) Is it worth it? ${ }^{34}$ Owing to these factors, the IDEAL collaborative, the DoH, NICE, policy-makers and commissioning groups have called for surgical registries to improve our evidence base, drive quality and safety improvements, and inform policy and guidelines development. ${ }^{13} 182627$

\section{Strengths and limitations}

A key strength of this study is its inclusive and robust approach, involving multiple stakeholder groups and patients with hearing loss. Moreover, our findings built on a conceptual framework on successful surgical registry development, developed following our systematic review. ${ }^{22}$ The approach enabled the collection of a rich dataset in a field where there is a paucity of empirical evidence and a high level of uncertainty. The interview schedules were informed by our published systematic literature review and were piloted before data collection. FGs and interviews were facilitated by individuals with expertise in qualitative interviewing, and patient and public involvement. Data were extracted and analysed by two independent data judges, with further verification by a data auditor. Participants were given an opportunity to discuss any other areas of registry development, not already covered by the questions and follow-ups.

Two limitations may restrict the generalisability of our findings. First, patients were selected from a UCL database of patients, with FGs taking place at the UCL Ear Institute. This resulted in the majority of patients being located in or near London. Second, the use of purposive sampling for identifying PSs may have been prone to researcher bias. However, we attempted to mitigate this limitation by cross-checking the sample with independent experts from external institutions, and by giving all interviewees the opportunity to suggest stakeholders for subsequent interviews.

\section{Implications}

This paper identifies the requirements for developing a successful national registry of auditory implants. Its approach and findings can be adopted on an international level to inform successful registry development in other countries.

A successful registry of auditory implants would help develop robust national policy and guidelines. It would also help promote research and innovation, improve healthcare quality and safety and help patients make decisions about their care. From a commissioning perspective, the registry would facilitate equitable access to care and efficient procurement of implants.

\section{CONCLUSION}

This study identifies the requirements for developing a successful national registry of auditory implants, benefiting from the involvement of numerous PS groups and patients with hearing loss. Our approach may be used internationally to inform successful registry development.

Acknowledgements We would like to thank John Phillips for his help in developing and testing the professional stakeholder interview schedule. We would also like to thank Aneeka Degun for Patient and Public Involvement expertise. We thank all patients and professional stakeholders for their input and contribution to this study. 
Contributors RM, AK, AWC, CT, EM, PL and AS made substantial contributions to the conception and design of the work. RM and AK collected the data. RM, $\mathrm{CT}, \mathrm{PL}$ and $\mathrm{AS}$ analysed the data. RM, AK, AWC, CT, EM, PL and AS were involved in drafting the article and revising it critically. RM, AK, AWC, CT, EM, PL and AS approved the final version to be published. RM, AK, AWC, CT, EM, PL and AS agree to be accountable for all aspects of the work in ensuring that questions related to the accuracy or integrity of any part of the work are appropriately investigated and resolved.

Funding AK and PL were supported by the National Institute for Health Research (NIHR) Collaboration for Leadership in Applied Health Research and Care South London at King's College Hospital NHS Foundation Trust. This work was supported by: a NICE Scholarship, UCL Public Policy Small Grants Scheme. All authors had complete access to the study data that support the publication.

Disclaimer The views expressed are those of the author(s) and not necessarily those of the NHS, the NIHR or the Department of Health. Funders were not involved in study design, data collection, data analysis, manuscript preparation or publication.

Competing interests None declared.

Patient consent Obtained.

Ethics approval Ethical approval was granted by UCL Research Ethics Committee 9031/001.

Provenance and peer review Not commissioned; externally peer reviewed.

Data sharing statement № additional data available.

Open access This is an open access article distributed in accordance with the Creative Commons Attribution Non Commercial (CC BY-NC 4.0) license, which permits others to distribute, remix, adapt, build upon this work non-commercially, and license their derivative works on different terms, provided the original work is properly cited, appropriate credit is given, any changes made indicated, and the use is non-commercial. See: http://creativecommons.org/licenses/by-nc/4.0/.

\section{REFERENCES}

1. Department of Health (DOH). 2015. Action plan on hearing loss. https://www.england.nhs.uk/wp-content/uploads/2015/03/act-planhearing-loss-upd.pdf 13 (accessed 12 Feb 2016).

2. Mandavia R, Dimitriadis PA, Monksfield P, et al. UK bone conduction hearing device consensus workshop: Narrative summary. Cochlear Implants Int 2017;18:187-91.

3. Generate. The Research Agenda for ENT, Hearing and Balance Care. A UK Partnership of Patients, Professionals and the Public. 2016. https://entuk.org/sites/default/files/files/Research\%20Agenda\% 20ENT\%20Hearing\%20and\%20Balance\%2030\%2011\%2015.pdf (accessed 14 April 2017).

4. Lamb B, ONeill C, Atkins J. The real cost of adult hearing loss. httpwww.earfoundation.org.uknewsarticles (accessed 16 Apr 2017).

5. Anon. Hearing loss: an important global health concern. Lancet 2016;387:2351.

6. Blazer DG, Domnitz S, Liverman CT. Committee on Accessible and Affordable Hearing Health Care for Adults, Board on Health Sciences Policy, Health and Medicine Division, National Academies of Sciences, Engineering, and Medicine. Hearing Health Care for Adults. Washington, D.C: National Academies Press, 2016. (accessed 2 Nov 2016)

7. Wilson BS, Tucci DL, Merson MH, et al. Global hearing health care: new findings and perspectives. Lancet 2017;390:2503-15.

8. Wilson JA, Steen IN, Lock CA, et al. Tonsillectomy: a cost-effective option for childhood sore throat? Further analysis of a randomized controlled trial. Otolaryngol Head Neck Surg 2012;146:122-8.

9. Crowson MG, Ryan MA, Rocke DJ, et al. Variation in tonsillectomy rates by health care system type. Int $J$ Pediatr Otorhinolaryngol 2017;94:40-4.
10. Livingston G, Sommerlad A, Orgeta V, et al. Dementia prevention, intervention, and care. Lancet 2017;390:2673-734.

11. Lin FR, Metter EJ, O'Brien RJ, et al. Hearing loss and incident dementia. Arch Neurol 2011;68:214-20.

12. NHS Commissioning Board (CB). 2013. Clinical Commissioning Policy: active middle ear implants. https://www.england.nhs.uk/ commissioning/wp-content/uploads/sites/12/2013/04/d09-ps-a.pdf (accessed 12 Nov 2016)

13. NHS Commissioning Board (CB). 2013. Clinical Commissioning Policy: bone anchored hearing aids. https://www.england.nhs.uk/wpcontent/uploads/2013/04/d09-p-a.pdf (accessed 15 Aug 2016).

14. Ear Foundation. 2015. National bone conducting hearing implant registry. httpwww.earfoundation.org.ukhearing-technologiesboneconducting-hearing-implantsnational-bone-conducting-hearingimplant-registry (accessed 16 Sep 2016).

15. Oulharj S, Pauchot J, Tropet Y. PIP breast implant removal: a study of 828 cases. J Plast Reconstr Aesthet Surg 2014;67:302-7.

16. Smith AJ, Dieppe P, Vernon K, et al. Failure rates of stemmed metalon-metal hip replacements: analysis of data from the National Joint Registry of England and Wales. Lancet 2012;379:1199-204.

17. Mandavia R, Carter AW, Haram N, et al. An evaluation of the quality of evidence available to inform current bone conducting hearing device national policy. Clin Otolaryngol 2017:42:1000-24.

18. Hickey GL, Cosgriff R, Grant SW, et al. A technical review of the United Kingdom National Adult Cardiac Surgery Governance Analysis 2008-11. Eur J Cardiothorac Surg 2014;45:225-33.

19. National Hip Fracture Database NHFD workstream delivery team. National Hip Fracture Registry Annual Report. 2015.

20. The NJR Editorial Board. National Joint Registry 12th Annual Report. 2017.

21. Gliklich RE, Dreyer NA, Leavy MB. Registries for evaluating patient outcomes: a user's guide. 3rd edn. Rockville (MD): Agency for Healthcare Research and Quality (US), 2014. (accessed 2 Sept 2016).

22. Mandavia R, Knight A, Phillips J, et al. What are the essential features of a successful surgical registry? a systematic review. BMJ Open 2017;7:e017373.

23. Hsieh HF, Shannon SE. Three approaches to qualitative content analysis. Qual Health Res 2005;15:1277-88.

24. Tong A, Sainsbury P, Craig J. Consolidated criteria for reporting qualitative research (COREQ): a 32-item checklist for interviews and focus groups. Int J Qual Health Care 2007;19:349-57.

25. Robinson OC. Sampling in interview-based qualitative research: a theoretical and practical guide. Qual Res Psychol 2014;11:25-41.

26. House of Commons Science and Technology Committee (HCSTC). 2012. Regulation of Medical Implants in the UK and EU. http://www. publications.parliament.uk/pa/cm201213/cmselect/cmsctech/163/ 163.pdf (accessed 12 Oct 2016).

27. McCulloch P, Cook JA, Altman DG, et al. IDEAL framework for surgical innovation 1: the idea and development stages. $B M J$ 2013;346:f3012.

28. Black N. Why we need observational studies to evaluate the effectiveness of health care. BMJ 1996;312:1215-8.

29. Roseman M, Milette K, Bero LA, et al. Reporting of conflicts of interest in meta-analyses of trials of pharmacological treatments. JAMA 2011;305:1008-17.

30. Bekelman JE, Li Y, Gross CP. Scope and impact of financial conflicts of interest in biomedical research: a systematic review. JAMA 2003;289:454-65.

31. Bhandari M, Busse JW, Jackowski D, et al. Association between industry funding and statistically significant pro-industry findings in medical and surgical randomized trials. CMAJ 2004;170:477-80.

32. Karanicolas PJ, Farrokhyar F, Bhandari M. Practical tips for surgical research: blinding: who, what, when, why, how? Can J Surg 2010;53:345-8.

33. Elson DW, Dawson M, Wilson C, et al. The UK Knee Osteotomy Registry (UKKOR). Knee 2015;22:1-3.

34. Andermann A, Pang T, Newton JN, et al. Evidence for Health II: Overcoming barriers to using evidence in policy and practice. Health Res Policy Syst 2016;14:17. 